Cad.Est.Ling., Campinas, (42): 147-154, Jan./Jun. 2002

\title{
À MEMÓRIA DE PAUL TEYSSIER
}

\author{
"Elogio fúnebre do Professor Paul TEYSSIER \\ pronunciado por seu discípulo e amigo Albert \\ AUDUBERT, ex-professor de Lingua e Literatura \\ Francesas na Univerisdade de São Paulo, por \\ ocasião da missa celebrada no dia 29 de janeiro de \\ 2002 pelo reverendo ARMOGATHE, capelão da \\ École Normale Supérieure, na igreja de Saint \\ Séverin, em Paris.
}

ALBERT AUDUBERT

Há duas semanas, levamos para sua amada terra limusina os restos mortais de nosso amigo Paul TEYSSIER, falecido repentinamente no dia 10 de janeiro, quando voltava para sua residência em Meudon, no final de mais uma jornada de trabalho. Acolheu-o o túmulo de família próximo à cidade de Uzerche, no município de Condatsur-Ganaveix. Na aldeia de Vernéjoux, era proprietário com o irmão Louis de uma ampla e formosa mansão, herança paterna, em meio à pradaria e aos castanhais; durante toda a vida, essa mansão foi seu local predileto para as temporadas de férias: uma casa que abrigava sem apertos sua família de quatro filhos, acrescida mais tarde de sete netos. O reverendo ARMOGATHE acaba de nos lembrar em seu sermão com quanto prazer o patriarca que ele se havia tornado com o correr dos anos exercia aí a arte de ser avô. Ele e a esposa tinham orgulho de sua descendência. Ele deixava porém aflorar um motivo de tristeza: nessa descendência não havia um estudioso das letras - entendase: alguém que tivesse passado pela Ecole Normale Supérieure - para continuar sua missão no futuro. Quem sabe, talvez um dia, Hector o bisneto?

Correziano de antiga cepa, ele evocava com freqüência a fazenda que seu tio tinha em La Geneste, lugar de pescarias nos afluentes então piscosos do rio Vézère. Na época das férias escolares, seu grande amigo André MONTEIL vinha freqüentemente juntar-se a ele.

Seu pai era médico. Encontrava-se mobilizado na primeira guerra mundial quando Paul nasceu, em 12 de dezembro de 1915, em Argentan, segundo de três irmãos, na planície cara a Péguy, a Beauce. Depois da guerra, o doutor instala seu consultório na mesma região, em Cloyes-sur-le-Loir, e assim Paul completará sua escolaridade na vizinha cidade de Vendôme. Aluno brilhante, ele é aceito para os preparatórios à Escola Normal Superior de Letras no Lycée Louis-le-Grand, em Paris, e é selecionado para a École Normale Supérieure. Ele havia conhecido André MONTEIL num encontro de 
jovens católicos da J.E.C., em Lyon, quando tinham por volta de quinze anos; depois, eles se reencontrariam no Lycée Louis-le-Grand (André vinha do Collège Cabanis de Brive), e na mesma École Normale Supérieure.

Os dois fazem juntos o concurso da Agrégation em Gramática. André é, também um correziano de quatro costados, de Juillac, por parte de mãe, e de Végennes (próximo a Beaulieu-sur-Dordogne), por parte de pai. Por essa procedência explica-se o fato de que domina perfeitamente as duas normas do occitano falado no departamento da Corrèze, a saber, o limusino, ao norte, e o querciniano ao sul. Quanto a ele, Paul TEYSSIER conhecia muito bem a língua dos trovadores. Eles se entregam então a intermináveis lições de filologia, de um lado e de outro da linha isoglossa que atravessa o sul do departamento. Originário da mesma Végennes, de língua materna querciniana e ainda por cima gramático, eu tinha sido apresentado a Paul TEYSSIER por nosso amigo comum, quando de minha nomeação para a Universidade de São Paulo, nos anos sessenta. Com apenas uma geração de atraso, eu tinha pego o bonde andando nos debates dos dois e em suas discussões cheias de erudição, que se abriam naturalmente para as línguas clássicas e românicas. André MONTEIL tinha trocado havia tempo o cargo de professor por uma brilhante carreira política: deputado, prefeito, ministro, senador. Ele nos deixou em fins de 1998 e também descansa na Corrèze, em Collongesla-Rouge.

Não demorou para que o mestre me honrasse com sua amizade. Eu o recepcionei várias vezes em suas missões no Brasil. Ele gozava aí do mesmo prestígio que em Portugal, e ficava igualmente à vontade, passando com extrema facilidade de uma pronúncia à outra. Seu Manuel de grammaire portugaise, editado por Klincksieck, no qual as duas normas, portuguesa e brasileira, são descritas em paralelo pela primera vez, é um modelo para esse gênero de obra.

Durante uma viagem a Portugal, que fiz em sua companhia, pude avaliar in loco todo o respeito e a consideração que tinham por ele naquele país. Era setembro de 1975. Dezoito meses depois de ter eclodido, a Revolução dos Cravos continuava à procura de um rumo e a incerteza permanecia. Acontecimentos graves tinham ocorrido durante o verão e continuavam agitando o país. Vistos de longe, eles pareciam um longo happening político-revolucionário, mas havia o risco de que se precipitassem e levassem para o pior. Nós tínhamos curiosidade de ir ver tudo mais de perto, no próprio local. Paul TEYSSIER só tinha conhecido o Portugal entorpecido do Salazarismo, queria compreender. Descobri então, não obstante as dificuldades do momento, como as portas se abriam em toda parte para Monseiur TEYSSIER. Personalidades políticas importantes, freqüentemente de origem universitária, entre elas um futuro presidente da República, suspendendo qualquer outra atividade, se apressavam em recebê-lo para comentar a situação. Ao longo da viagem, que durou um mês, íamos lendo seu excelente Nous partons pour le Portugal (P.U.F. 1963) que, muito mais do que um simples guia turístico, é um verdadeiro tratado de história e de cultura. Ele queria que fosse reeditado.

Para mim, esse setembro ficou inesquecível.

Mas eu estou me adiantando. Preciso retornar brevemente à época em que nosso amigo nem sequer sonhava em tornar-se professor de português. E não é uma época 
qualquer! Estamos em 1939, bem às vésperas da segunda guerra mundial. Ele acaba de obter o título de agrégé, e é recém-casado. Tendo recebido preparação militar na Ecole Normale, é promovido a oficial na Academia Militar de Saint Maixent e participa da "drôle de guerre". É aprisionado pelos alemães em Antony, na região parisiense, com seu colega, o futuro Ministro das Relações Exteriores Jean SAUVAGNARGUES. Mas logo consegue fugir: o nascimento de seus dois gêmeos deu-lhe asas.

Desmobilizado, obtém seu primeiro emprego no Lycée Edmond Perrier de Tulle, onde permanece apenas por um ano. Mas esse ano basta para que se manifestem e sejam reconhecidas as qualidades pedagógicas e a sensibilidade do grande professor que ele se tornará mais tarde. Não posso deixar de citar algumas linhas do Bulletin des lettres, sciences et arts de la Corrèze de 1996, que pediu a várias personalidades originárias do departamento que falassem de sua infância ou de sua mocidade passadas no lugar. André MONTEIL o tinha feito. Paul TEYSSIER tinha sido contatado. Um aluno da Escola Normal de professores primários de Tulle, turma de 1940, que se preparava então para o baccalauréat no mesmo Lycée Edmond Perrier, dá o seguinte depoimento: "Que sorte, ter tido um professor de francês de qualidade excepcional como Paul TEYSSIER! Esse professor não só marcou nossas inteligências, mas ainda formou nossas sensibilidades, ou antes, nos deu novas sensibilidades. Com ele, a linguagem quotidiana adquiria uma realidade nova, musical e poética. Despertávamos para a beleza das palavras. Aprendíamos que não se devia dizê-las de passagem, senão deixando-as ser, como se estivessem prestes a sair do uso para significar de outro modo, e apenas para fins de beleza. Longe do dia-a-dia e dos valores triviais, o professor TEYSSIER nos fazia descortinar nas palavras dos poetas distâncias, horizontes, climas, chamados nunca ouvidos, cantos de sereias. Assim, em cada uma de suas aulas, ele nos levava para uma viagem no azul. O que foi feito dele? Muitas vezes me fiz essa pergunta... Fiquei sabendo que, depois de uma carreira brilhante, ele vive uma aposentadoria tranquila, perto de Condat-sur-Ganaveix, estudando os trovadores."

Assim falava o futuro filósofo Marcel CONCHE, hoje professor emérito da Sorbonne, originário de Altillac, perto de Beaulieu. Mas como pôde desconhecer que Paul TEYSSIER era, como ele, professor emérito da mesma Universidade de Paris?

No Lycée de Tulle, encontramos, repito, um Paul TEYSSIER que ainda não conhece o português.

Nessa época, para o Ministério da Educação Nacional, trata-se ainda de uma língua "rara", como o são também o árabe, o russo ou o chinês... Ainda não há formação específica em português na Universidade, e por conseguinte não há ensino do português no secundário. Será preciso esperar pelo ano de 1974, para que aconteça o primeiro concurso de agrégation nessa área. Paul TEYSSIER e seu colega da Universidade de Paris III, o decano Raymond CANTEL, têm participação ativa nesse processo e presidem as primeiras bancas. Em suma, ele fez parte dessa geração de pioneiros que foram se chegando ao português por caminhos indiretos, se assim posso dizer. E é no mais das vezes ao ser enviado ao exterior em missão como professor de francês ou como diretor de Instituto, que um professor com título de agrégé, de início necessariamente obtido em outra disciplina, poderá especializar-se em português, ser habilitado para o ensino dessa matéria e, feita a tese, tornar-se professor universitário. 
Ele tinha ouvido falar do Service des oeuvres, que tratava do ensino no exterior, e do qual se originaria o setor das Relations culturelles, scientifiques et techniques do Quai d' Orsay, para onde ele próprio seria designado mais tarde. Oferecem-lhe um cargo de leitor no exterior, mas é preciso que seja num país neutro, e países neutros não há muitos no início dos anos quarenta: Suíça, Suécia ou Portugal, para escolher. Em julho de 1941 oferecem-lhe que assuma no reinício das aulas a Ecole française de

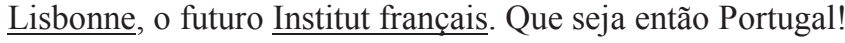

Depois, em 1944, ele se transfere de Lisboa para o Porto, como diretor do Institut français, aí permanecendo até 1947. Esses seis anos de Portugal serão evidentemente determinantes para sua futura carreira de lusitanista. Mas nesse momento ele volta a Paris, para responder por uma missão junto à Direction générale des Relations Culturelles, scientifiques et techniques. Na época, vários professores são designados pela Education Nationale para aquele órgão, do qual já falei, assim como muitos são designados para os cargos de Conselheiro cultural no exterior, junto às Embaixadas. Depois da experiência portuguesa, ele estará ainda mais próximo do mundo discreto da diplomacia, do qual aprenderá muito rapidamente a dominar as sutilezas. A tal ponto ponto que, mais tarde, poderá desempenhar sem dificuldade as funções de Conselheiro Cultural.

Por algum tempo, depois dessa missão no Quai d' Orsay que termina em 1953, ele volta ao magistério, mas desta vez como professor de português, na Faculdade de Letras de Toulouse. Aí, ele dá continuidade às pesquisas referentes à sua tese principal de doutoramento, sobre la langue de Gil VICENTE, o dramaturgo do início do século XVI que criou o teatro português. Essa tese será defendida na Sorbonne em 1956. Ela é fundamental, eu diria mesmo fundadora em relação à obra de Paul TEYSSIER, e continua sendo uma obra de referência.

Depois, ele deixa Toulouse e, por algum tempo, também o ensino, a fim de tornarse Conselheiro Cultural junto à Embaixada da França em Túnis e chefe da missão universitária e cultural francesa na Tunísia. O embaixador é seu colega de Escola Normal Georges GORSE. Com a independência, Habib BOURGUIBA tornou-se presidente da República Tunisiana. Há tumultos violentos em Bizerta. O embaixador é chamado de volta para a França e sobra para o Conselheiro Cultural a pesada tarefa de cuidar da segurança e do repatriamento da missão francesa. A situação é um barril de pólvora.

Ouvi várias vezes de Paul TEYSSIER. o relato desses dias de chumbo, da tensão extrema crescendo, os apelos feitos a BOURGUIBA, no limite da explosão. Ele era um narrador notável, e um ator completo. Sabia imitar, fazer mímica, engrossar a voz, praguejar, simular a raiva e também controlá-la quando não era de mentira. Denunciava com eloquência as desordens do mundo ou as extravagâncias da politica. Ouvi-lo era sempre uma delícia. Ele deixa Tunis em 1961, mas o tempo foi suficiente para que entrasse em contato com a cultura muçulmana e a língua árabe, que tanto influenciaram o mundo ibérico. Vários artigos atestam esse interesse.

Depois de uma breve passagem em 1962 pela direção do Institut français de Nápoles, outra fonte inesgotável de recordações pitorescas, é nomeado Conselheiro cultural da Embaixada da França em Roma e chefe da missão universitária e cultural 
francesa na Itália. Ele aperfeiçoa seus conhecimentos já profundos das línguas românicas acrescentando-lhes o do italiano. Pode-se dizer que é um dos raros franceses que podem rivalizar com os grandes romanistas que são, por exemplo, os alemães ou os suiços; estes, recebem em sua pátria, uma formação específica, a romanística, que não existe no currículo universitário francês. Se acrescentarmos o inglês e o alemão e sua curiosidade pelo japonês, temos uma panóplia verdadeiramente completa.

Em 1967, ele deixa a Itália para voltar para a África, mas desta vez vai para o Senegal, na África negra, na qualidade de Reitor da Academia de Dakar. Ele será o último reitor francês dessa instituição. Como se pode imaginar, sua atividade vai além da administração escolar e universitária. Ele se liga ao gramático-poeta-presidente Léopold Sédar SENGHOR (do português SENHOR), que procurará segurá-lo no Senegal por mais tempo. (Que coincidência! No exato instante em que estou falando aqui, o cardeal arcebispo de Paris está celebrando uma missa solene na igreja de SaintGermain-des-Prés, pela alma do presidente SENGHOR. Unamo-los em nossa recordação).

Interessa-se naturalmente pelas línguas vernáculas, em particular o wolof, mas bem mais pelos crioulos, em particular os da região da Casamança, cujo léxico é frequentemente de origem portuguesa. Mais tarde, dirigirá seminários na Sorbonne, e apresentará comunicações em congressos sobre esses temas.

É em 1971 que se encerra essa longa e rica parte da carreira de Paul TEYSSIER em que se alternaram, na maior parte do tempo no exterior, períodos de ensino e períodos de administração. Quem poderia estar mais preparado do que ele para assumir as funções da cadeira de língua e literatura portuguesa criada para ele na Universidade de Paris-Sorbonne, Paris IV? A essa altura ele é Cavaleiro da Legião de Honra, de que se tornará a seguir Oficial, Oficial da Ordem do Mérito Nacional, Oficial das Palmas Acadêmicas. E além disso, Oficial da Ordem da Instrução Pública em Portugal, Oficial da Ordem Nacional do Cruzeiro do Sul no Brasil, Benemerito delle Scuole e della Cultura e Commendatore dell' Ordine al Merito della Repubblica Italiana, na Itália, Comendador da Ordem Nacional do Senegal. É membro corresponente da Academia das Ciências de Lisboa. Está prestes a tornar-se o presidente do Conselho de administração da Maison du Brésil na Cité Universitaire de Paris, onde se empenhará na restauração hoje finalmente terminada do prédio sede, obra arquitetônica construída em 1959 segundo o projeto de LE CORBUSIER e Lúcio COSTA.

Com paixão, exercia paralelamente as atividades de professor e pesquisador, que se alimentam reciprocamente. Preparava minuciosamente suas aulas, seus seminários, suas conferências. Tinha horror ao vago, ao vaporoso, ao impreciso, à névoa do pensamento. Desde seus sólidos estudos clássicos, sempre tinha cultivado a clareza. E quando cruzava com o hermético GUIMARÃES ROSA, não parava de explorar em profundidade, de explicar, no sentido etimológico, os inesgotáveis recursos linguageiros daquele autor.

Desde sua tese sobre Gil VICENTE, o primordial de suas pesquisas era o amplo campo da lusofonia, que abrange vários continentes. Ele tinha refeito por sua própria iniciativa até o Oriente a rota das antigas caravelas portuguesas. 
Tinha estudado os primeiros dicionários latino-portugueses e portugueses-latinos de , Jerônimo CARDOSO, o homólogo português de Robert ESTIENNE. Esse gosto pela língua se reencontra em duas publicações mais importantes, que se tornaram clássicas: o Manuel de langue portugaise, já citado, editado por Klincksieck (cuja primeira edição data de 1976) e a Histoire de la langue portugaise, publicado pelas Presses Universitaires de France, que contém uma descrição admirável desta língua, nos limites apertados de um volume da coleção "Que sais-je?" (1980); a tradução para o português dessa obra caberia, em 1982, a seu amigo brasileiro, o grande lingüista Celso CUNHA. TEYSSIER foi autor de edições críticas e de muitas traduções para o francês de obras clássicas e modernas, por exemplo de Os Maia de EÇA DE QUEIROZ, reeditada várias vezes; ou de Gil VICENTE: Auto da Barca do Paraíso (Bibliothèque de la Pléiade - Théâtre espagnol du XVIème siècle - Gallimard 1983) - $\underline{\text { Triunfo do }}$ inverno e da primavera (Chandeigne 1997) - A Barca do Inferno (Chandeigne 2000). Coordenou a parte brasileira do Dictionnaire universel des Littératures (P.U.F.). Mas suas traduções não ficam limitadas ao português. Quando a morte o surpreendeu, acabava de terminar Voyage en Arabie et aux Indes, tradução de um relato de Ludovico di VARTHEMA, viajante italiano do século XVI, a qual se acrescentará à série de brilhantes obras já publicadas pelo editor Chandeigne, entre as quais se incluem Esclave à Alger e o relato Voyages de Vasco da Gama. Recentemente, ele tinha colaborado com o Lexicon der Romanistischen Linguistik. Atualmente no prelo, e também pelo editor Chandeigne, deve ser lançado em 2003 L'intercompréhension romane: du français à l'espagnol, à l'italien, au portugais. Duas obras publicadas pela Fundação Calouste Gulbenkian mostram em síntese a amplitude e variedade de suas pesquisas: Etudes de littérature et de linguistique (Paris 1990) e uma alentada coletânea organizada em sua homenagem, por ocasião de sua aposentadoria, que aconteceu em 1987 (volume XXIII dos Arquivos do Centro Cultural português).

Tinha sempre batalhado para promover os estudos portugueses na França, por exemplo no âmbito da Association pour le développement des études portugaises, brésiliennes, d'Afrique et d'Asie lusophones, a ADEPBA, e, fora da França, através de numerosíssimas missões e de sua atuação como professor convidado. Sua autoridade intelectual se exercia também nas diferentes responsabilidades de presidente de banca, de concurso ou tese, na participação em comissões assessoras e em comissões de avaliação; tinha sido diretor da Unidade de Ensino e Pesquisa de Estudos Ibéricos e Latino-americanos da Sorbonne. Já aposentado, orgulhava-se de ter sido convidado por Portugal para participar de uma comissão de avaliação das universidades portuguesas. Pode-se dizer que ele era um Senhor, um Monsieur, um grand Monsieur, e eu diria mesmo um Seigneur.

Paul TEYSSIER trabalhou além dos limites que a idade costuma impor. Parecia ter superado a contento alguns graves problemas de saúde que sobrevieram nos últimos anos. Tinha conseguido retomar suas atividades, e levar uma vida normal. Já citei sua última tradução do italiano, que sairá como publicação póstuma. Tinha ainda, em andamento, a tradução para o português de sua tese sobre Gil VICENTE, que, curiosamente, nunca foi feita antes; mas esse trabalho sempre pôde ser adiado, afinal 
nossos amigos portugueses dominam perfeitamente o francês, continuando uma tradição que remonta a seus grandes humanistas do século XVI.

Não tenhamos dúvidas: sempre haveria alguma obra em sua bancada.

Mas a morte o fulminou, "tels ces chênes qu' on abat", para usar a bela imagem que MALRAUX retomou de Vitor HUGO para aplicá-la ao General DE GAULLE, brutalmente desaparecido em 1970

Retomo, para terminar, um breve poema sobre a morte, do grande poeta brasileiro Manuel BANDEIRA. Notar-se-á que esse poema evita cuidadosamente as palavras "morte" e "morrer". Tem-se a impressão de que o poeta ultrapassou as fronteiras da vida, e já tem grande intimidade com sua visitadora, que ele a acolhe mesmo sem tê-la chamado. Ele a espera tranquilamente como uma visita corriqueira, depois que a noite caiu. Vão se encontrar, e tomar juntos uma leve refeição noturna. O título do poema é CONSOADA:

Quando a indesejada das gentes chegar

(Não sei se dura ou caroável),

Talvez eu tenha medo.

Talvez sorria, ou diga:

- Alô, ineludível!

O meu dia foi bom, pode a noite descer,

(A noite com seus sortilégios).

Encontrará lavrado o campo, a casa limpa,

A mesa posta.

Com cada coisa em seu lugar.

\section{BIBLIOGRAFIA DE PAUL TEYSSIER}

\section{I - LIVROS}

1. La langue de Gil Vicente. - Paris, Klincksieck, 1959 (tese principal para o Doctorat d' état)

2. Nous partons pour le Portugal. Presses Universitaires de France, 1963. Reeditado em 1970.

3. Manuel de langue portugaise (Portugal-Brésil), Paris Klincksieck, 1976. Reeditado em 1984. Tradução portuguesa Manual de língua portuguesa. Coimbra Editora, 1989.

4. Histoire de la langue portugaise. Paris, Presses Universitaires de France, 1980. Tradução portuguesa História da Língua Portuguesa, Sá da Costa, 1982. 7a. edição, 1997.

5. Gil Vicente, o autor e a obra. - Lisboa, ICALP. Biblioteca breve, 1982.

6. Etudes de littérature et de linguistique. - Paris, Centre culturel C. Gulbenkian, 1990.

7. Dictionnaire de littérature portugaise. - Paris, Presses Universitaires de France, 1994.

$$
\text { no prelo: }
$$

8. A língua de Gil Vicente, nova edição aumentada. - Lisboa, Imprensa Nacional.

9. L'intercompréhension romane: du français à l' espagnol, à l' italien, au portugais - Chandaigne, 2003 


\section{II - EDIÇÕES CRÍTICAS E TRADUÇÕES}

1. Eça de Queiroz, Les Maia - 1a. edição, Club Bibliophile de France. 2a. ed. P.U.F / Fundação Calouste Gulbenkian, 1971; 3a. ed. Société des Éditions Portugaises, 1982; 4a. edição revista e corrigida, Chandaigne, 1997; reeditada em 2001.

2. Simão Machado, Comédia de Dio, edição crítica, com introdução e comentário de Paul Teyssier. Istituto di filologia romanza dell’Universidade de Roma / Edizioni dell' Ateneo, 1969.

3. Gil Vicente, Romagem d'Agravados. edição crítica, com introdução e comentário de Paul Teyssier. Editions Hispaniques, 1975.

4. Gil Vicente, "Auto de la sibylle Cassandre”, "Auto de la Barque du Paradis", "Tragicomédie de Dom Duardos”, em Théâtre espagnol du XVIème siècle. Pléiade Gallimard, 1983.

5. Esclave à Alger. Récit de captivité de João Mascarenhas (1621-1626), tradução, introdução e notas de Paul Teyssier - Chandeigne, Coleção Magellane, 1993; 2a. edição, 1999.

6. Voyages de Vasco a Gama. Relations des expéditions de 1497-1499 et de 1502-1503, tradução, introdução e notas de Paul Teyssier. - Chandeigne, Coleção Magellane, 1993; 2a. edição revista, 1999.

7. Gil Vicente, La plainte de Maria Parda, edição crítica bilíngue, tradução, introdução e notas de Paul Teyssier. - Chandeigne, 1995.

8. Gil Vicente, Triomphe de l' hiver et du printemps, edição crítica bilíngue, tradução, introdução e notas de Paul Teyssier. - Chandeigne, 1997.

9. Gil Vicente, La barque de l'Enfer, edição crítica bilíngue; tradução, introdução e notas de Paul Teyssier. - Chandeigne, 2000.

$$
\text { no prelo: }
$$

10. Voyage an Arabie et aux Indes de Ludovico di Varthema (1503-1508) - tradução do italiano, introdução e notas de Paul Teyssier - Chandeigne, Coleção Magellane. 


\section{N C O G N I T O}

Revue internationale francophone en Sciences Cognitives

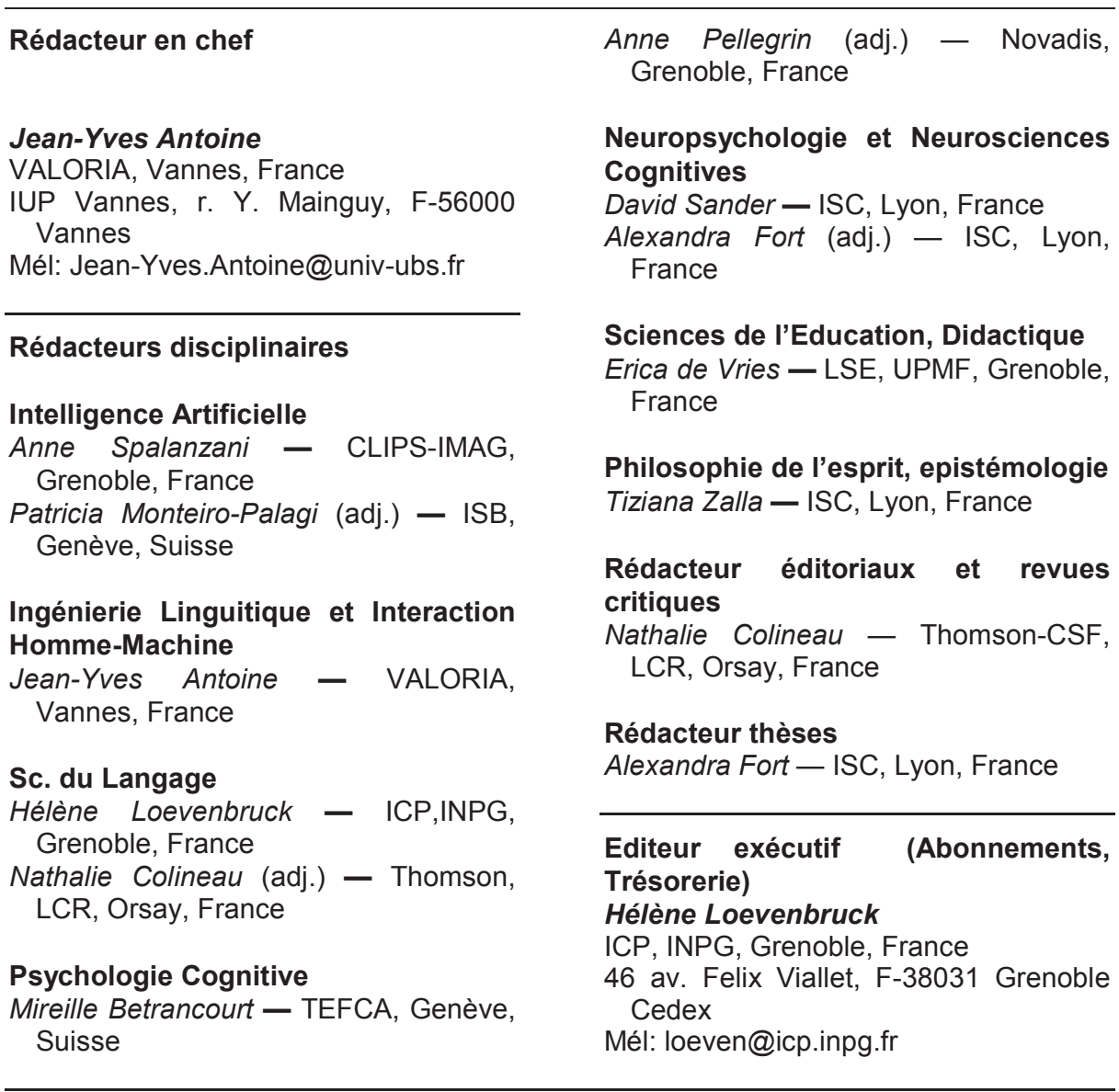

Objectifs - IN COGNITO est une revue trimestrielle pluridisciplinaire publiant des articles théoriques, techniques ou expérimentaux concernant tous les aspects de la cognition et de sa simulation. Elle concerne l'intelligence artificielle et ses applications (vision, communication homme-machine, traitement automatique des langues, etc.), les neurosciences, la psychologie, la linguistique et les sciences du langage, la philosophie, la sociologie, l'épistémologie, l'éthologie, la biologie, la didactique et les sciences de l'éducation, etc.

Diffusion - La revue est diffusée à la fois sous version papier et version électronique (voir "Abonnements"). Dotée d'un comité scientifique international, sa diffusion concerne essentiellement l'espace francophone ainsi que l'Europe de l'Est et l'Amérique Latine.

Publications - Chaque numéro de la revue regroupe plusieurs types de publications : 
- articles, revues critiques de publications

longueur libre (30 pages maximum conseillé)

- résumés de thèse, présentations de laboratoires 2 pages maximum

Soumission - Les articles soumis doivent être adressés, sous format papier (cinq exemplaires) ou électronique (Word format RTF) au rédacteur en chef de la revue. Afin d'assurer une évaluation "en aveugle" de l'article, la page de titre ne doit comporter aucune référence aux auteurs. De même, le corps de l'article ne doit pas révéler l'identité des auteurs, ni leur affiliation. Une feuille d'identification à part précisera le titre de l'article, le nom et les coordonnées des auteurs ainsi que les mots-clefs.

Format de soumission - La langue de publication est le français. Les articles sont au format A4 avec marges latérales de $2 \mathrm{~cm}$ et horizontales de $2,5 \mathrm{~cm}$ (en-tête et pied de page à $1,5 \mathrm{~cm}$ du bord) et dactylographiés avec la police Arial; l'interligne est simple. L'entête de l'article comportera le titre, le nom des auteurs et leur coordonnées, suivi d'un résumé, le tout sur une seule colonne. Le corps de l'article est rédigé sur deux colonnes espacées de $1 \mathrm{~cm}$ (police taille 9). Tout début de paragraphe se traduit par un espacement supérieur d'une $1 / 2$ ligne. On distingue :

- titre de niveau 1 (exemple : 1.) espacement supérieur 18 pts, caractères minuscules gras, taille 12 , justifié à droite et à gauche.

- titre de niveau 2 (exemple : 1.1.) espacement supérieur 12 pts, caractères minuscules gras, taille 10, justifié à gauche.

Le format détaillé se trouve sur notre site Internet à l'adresse:

http://www-leibniz.imag.fr/RESEAUX/incognito/revue/infoinco.html

Evaluation - Hormis les résumés de thèse, qui font l'objet d'une vérification rapide, tout article est évalué par quatre membres du comité de lecture (trois spécialistes du champ disciplinaire concerné et un expert extérieur à la discipline). Cette évaluation tient compte de la qualité et de l'originalité du travail exposé, mais aussi de la clarté de l'article et de l'ouverture pluridisciplinaire dont il témoigne. Le comité de rédaction s'attache à assurer une évaluation (3 mois) et une publication rapide des articles soumis.

\section{Abonnements}

L'abonnement couvre une année de publication (quatre numéros) à partir de la réception du bulletin d'abonnement. II donne droit, sur demande, à l'adhésion gratuite à l'association In Cognito. Vous disposez de plusieurs modes de distribution correspondant à des tarifs différents :

- Abonnement WWW : récupération d'une version électronique (fichier Postcript, PDF ou document Word RTF) avec accès par mot de passe,

- Abonnement papier recu par envoi postal.

Règlement par chèque à l'ordre de:

Association In Cognito, INPG, 46 avenue Felix Viallet, F-38031 Grenoble Cedex, France.

Pour les abonnements à tarifs réduits (étudiants, chômeurs, militaires du contingent), joindre une photocopie de justificatif.

\begin{tabular}{lccc} 
Mode de distribution & Réduit & Individuels & Institutionnels \\
\hline \hline version électronique & $4 €($ Euros) & $8 €$ & $25 E €$ \\
Envoi postal France & $12,5 €$ & $20 €$ & $40 €$ \\
Envoi postal étranger & $15 €$ & $25 €$ & $45 €$
\end{tabular}




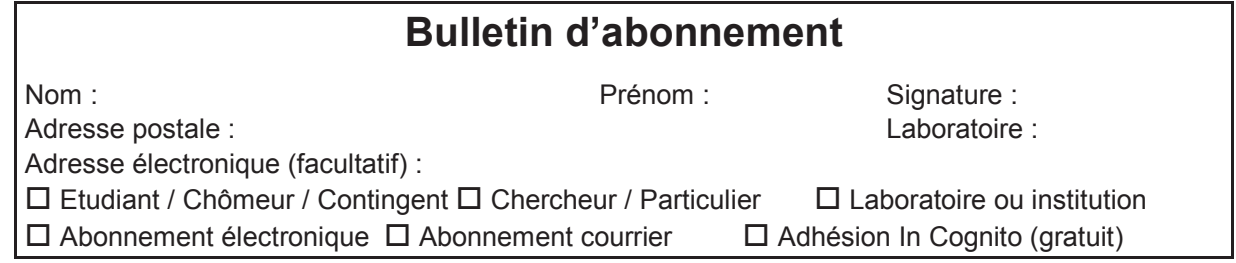




\section{N C O G N I T O}

Revue internationale francophone en Sciences Cognitives

\section{Comité Scientifique}

\section{ALLEMAGNE}

Krüger-Thielmann $\mathrm{K}$.

U. de Tübingen

AUSTRALIE

Colineau N.

CSIRO / IIT, North Ryde

Ozkan N.

CSIRO / IIT, North Ryde

\section{BELGIQUE}

Steels L.

Vanderdonckt J.

VUB AI Lab \& Sony Comp. Sc. Lab., Bruxelles

U. Catholique de Louvain

\section{BRESIL}

Barbosa T.

Unicamp, Campinas, Brésil

\section{CANADA}

Lapalme G.

Lefebvre B.

Moulin B.

Sélouani S.A.

\section{ESPAGNE}

Lopez de Mantaras R.

RALI, DIRO

SAFARI-UQAM, Montréal (Québec)

U. Laval, Ste Foy (Québec)

INST Telecom, Montréal (Québec)

ETATS-UNIS

Azzam S.

Salber D.

Tanné J.

FRANCE

Abry C.

Amy B.

Anceaux $\mathrm{F}$.

Antoine J.Y.

Aubergé V.

Baconnier $\mathrm{P}$.

Baker M.

Balacheff N.

Berthommier $\mathrm{F}$

Bianco M.

Bisseret A.

Boussaoud D.

Brassac C.

Caelen J.

Caelen-Haumont G.

Caro S.

Chaignaud $\mathrm{N}$.

Inst. Investig. IA, CSIC, Bellaterra (Catalogne)

Microsoft Research, Redmond, MA.

IBM TJ Watson Research Center, NY

Dept. of Neurology, Emory Univ., Atlanta

ICP, Grenoble

LEIBNIZ-IMAG, Grenoble

LAMIH-PERCOTEC, Valenciennes

VALORIA, Vannes

ICP, Grenoble

TIMC-IMAG, Grenoble

GRIC, COAST, Lyon

LEIBNIZ-IMAG, Grenoble

ICP, Grenoble

LSE, UPMF, Grenoble

INRIA Rhône-Alpes, Grenoble

INSERM Vision et Motricité, Lyon

L. Psychologie de l'Interaction, Nancy

CLIPS-IMAG, Grenoble

LPL, Aix en Provence

LIMCI, U. Bourgogne, Dijon

LIPN, Villetaneuse 
Claverie B.

Clerc M.

De Vries E.

Faïta F.

Fabre C.

Gayral F.

Genthial D.

Gordon M.B.

Graff C.

Guérin-Dugue A.

Habert B..

Haton J.P.

Hollard S.

Izaute $\mathrm{M}$.

Jouis $C$.

Lecomte A.

Lemaire $B$.

Lenca P.

Lestage $P$.

Lœvenbruck $\mathrm{H}$.

Luyat M.

Manes Gallo M.C.

Martin J.C.

Memmi D.

Menier G.

Nicolle A.

Nigay L.

N'Kaoua B.

Nugues $P$.

Orliaguet J.P.

Otman G.

Pellat J.

Pesty S.

Plenacoste P.

Raccah P.Y.

Robert-Demontrond $P$.

Rodet L.

Rossetti $Y$.

Sallaberry J.C.

Schmidt C.

Sébillot $P$.

Siroux J.

Szilas N.

Tiberghien G.

Tricot A.

Vernant D.

Weil G.

Zalla T.

\section{SUEDE}

Cerrato $\mathrm{T}$.
Lab. Sciences Cognitives, U. Bordeaux 2

France Telecom, Annecy

LSE, UPMF, Grenoble

Lab. Sc. Cognitives, U. Bordeaux 2

ERSS, Toulouse

LIPN, Villetaneuse

CLIPS-IMAG, Grenoble

CEA, SPSMS/MDN, Grenoble

L. Biologie du Comportement, Grenoble

LTIRF, Grenoble

ENS Fontenay St-Cloud

LORIA, Vandœuvre les Nancy

CLIPS-IMAG, Grenoble

U. Blaise Pascal, Clermont-Ferrand

IDIST, Lille

LORIA, Vandœuvre les Nancy

LSE, UPMF, Grenoble

LIASC, ENST Bretagne, Brest

L. Neuropsy. Expé., Bordeaux

ICP, Grenoble

L. URECA, Dépt Psychologie, Univ. Lille III

U. Montepellier 3

LIMSI, CNRS, Orsay

LEIBNIZ-IMAG, Grenoble

VALORIA, Vannes

GREYC, Caen

CLIPS-IMAG, Grenoble

UFR MI2S, U. Bordeaux 2

GREYC, Caen

LPE, Grenoble

INALF, Villetaneuse

Neurologie \& Neuropsy, CHU, Grenoble

LEIBNIZ-IMAG, Grenoble

TRIGONE, Lille

CeReS-CNRS, Paris

CREREG, IGR-IAE, Rennes

Novadis, Grenoble

INSERM, Vision et Motricité, Lyon

U. Bordeaux II

Pragmatique et Philo. du Lgge, Grenoble

IRISA, Rennes

IRISA-LLI, Lannion

Unilog, Paris

Institut des Sciences Cognitives, Lyon

IUFM Bretagne, Rennes

Philo. Lgge et Cognition, Grenoble

TIMC-IMAG, Grenoble

ISC-CNRS, Lyon, France

Iplab, NADA-KTH, Stockholm 


\section{SUISSE}

Bétrancourt M. TEFCA, U. Genève, Genève

Bouillon P. ISSCO, Genève

Bourlard $\mathrm{H}$ IDIAP, Martigny

Courant M. Institut d'Informatique, Fribourg

Ingold R. Institut d'Informatique, Fribourg

Monteiro-Palagi P. Institut suisse de bioinformatique, Genève

Derniers articles parus

\section{In Cognito (21) 2001}

J. Vauclair (CREPCO, France), Contraintes de comparaison des processus cognitifs chez le primate humain et non humain.

P. Kuntz et al. (IRIN, France) Vers un processus d'extraction de règles d'association centré sur l'utilisateur.

D. Déret, F. Jamet (Cognition et Didactique, U. Paris 8, France) Approche néopiagétienne de l'effet de récurrence dans le cadre des classifications complexes.

M. Quignard (GRIC-COAST, France) Modélisation cognitive des dialogues argumentatifs

In Cognito (19) 2000
NUMERO SPECIAL JEP'2000

\section{Journées d'Etude sur la Parole}

Sélection des meilleures contributions en traitement de la parole, linguistique et psycholinguistique

\section{In Cognito (18) 2000}

J.-E. Tyvaert (CIRLEP, U. Reims, France), Réflexions épistémologiques et programmatiques sur la place des langues dans la cognition humaine.
A. Spalanzani
(CNR, Italie), Évolution versus évolution darwinienne: pour l'adaptation des
systèmes de automatique de la parole

P. Dessus (LSE, UPMF, France), Constructions de connaissances par exposition à un cours avec LSA.

N. Thomasson (Rush Medical Center, Etats-Unis), L. Pezard (LNC, Paris, France), B. Renault (LENA-CNRS, France), Rémission d'épisodes dépressifs et réorganisation au sein de la dynamique cérébrale.

\section{In Cognito (17) 2000}

B. Laks (U. Paris X, France), Langage et cognition : invariants et variabilité.

C. Brun (L. de Gaulle, Ankara, Turquie), Un retour sur les origines classiques du réalisme intentionnel

D. Bovet (Language Research Center, Georgia State U., Etats-Unis), Conceptualisation et relations abstraites: comparaison entre l'enfant de trois ans et le babouin.

I. Kanellos, T. Thlivitis (LIASC, ENST Bretagne, France), A. Léger (CENT/DSM, France), Indexation anthropocentrée d'images au moyen de textes. 